\title{
MODIFIED STOPPA APPROACH FOR PELVIC AND ACETABULAR FRACTURE TREATMENT
}

\author{
STOPPA MODIFICADA PARA TRATAMENTO DE FRATURAS \\ PÉLVICAS E ACETABULARES
}

\author{
Hong-Zhang GUO ${ }^{1}$, YU-FANG HE ${ }^{2}$, WAN-QING $H E^{1}$ \\ 1. Department of Orthopaedics, Gansu Provincial Hospital of TCM, Lanzhou, China. \\ 2. The Third Hospital of Gansu Province, Lanzhou, China.
}

\begin{abstract}
Objective: A retrospective review aims to investigate the operative methods and therapeutic effects of the modified Stoppa approach for treating pelvic and acetabular fractures. Methods: 18 patients with acetabular fracture of the anterior column and pelvic anterior ring fracture underwent surgical treatment using the modified Stoppa approach. Some of the treatment was combined with the iliac fossa approach or rear K-L approach. Fracture reduction and postoperative function were evaluated using the Matta scoring standard and the Majeed scoring system. The Oxford Centre for Evidence-Based Medicine system was used to grade the literature review and create graded B recommendations. Results: Incision length was 6-12 cm (mean, $10 \mathrm{~cm}$ ), operative duration was 50-150 minutes (mean, 85 minutes), and intraoperative blood loss volume was 400-1,000 ml (mean, $500 \mathrm{ml}$ ). 18 patients were followed up for 12-36 months post-operation. In the results of $X$-ray films, 12 cases were anatomical reductions and the remaining cases were satisfactory reductions. According to Majeed standard, 13 patients were excellent and five patients were good. Conclusions: Treatment using the modified Stoppa approach was suitable for anterior approaches, in which pelvic and acetabular fractures were sufficiently exposed, the fracture was conveniently reduced, less complications occurred, and curative effect was satisfactory. Level of evidence III, Retrospective comparative study.
\end{abstract}

Keywords: Acetabulum. Fracture. Modified. Pelvic. Result. Stoppa.

\section{RESUMO}

Objetivo: Uma revisão retrospectiva tem como objetivo investigar os métodos operatórios e efeitos terapêuticos da abordagem modificada de Stoppa para o tratamento de fraturas pélvicas e acetabulares. Métodos: 18 pacientes com fratura acetabular da coluna anterior e fratura do anel anterior pélvico foram submetidos a tratamento cirúrgico utilizando a abordagem de Stoppa modificada. Parte do tratamento foi feita em conjunto com a abordagem da fossa ilíaca ou com a abordagem pelo acesso posterior de K-L. A redução da fratura e a função pós-operatória foram avaliadas pelo padrão de pontuação de Matta e o sistema de pontuação de Majeed. O sistema do Oxford Centre for Evidence-Based Medicine foi usado para classificar a revisão de literatura e criar as recomendações de grau B. Resultados: O comprimento da incisão foi de 6 a $12 \mathrm{~cm}$ (média de $10 \mathrm{~cm}$ ), a duração da cirurgia foi de 50 a 150 minutos (média de 85 minutos) e o volume de perda sanguínea intraoperatória foi de 400 a 1.000 ml (média de 500 ml). 18 pacientes foram acompanhados por 12-36 meses após a operação. Nos resultados dos filmes radiográficos, 12 casos foram de reduções anatômicas e os demais casos foram de reduções satisfatórias. De acordo com o padrão de Majeed, 13 pacientes foram considerados excelentes e cinco pacientes foram considerados bons. Conclusões: O tratamento que utilizou a abordagem de Stoppa modificada foi adequado para abordagens anteriores, nas quais as fraturas pélvicas e acetabulares estavam suficientemente expostas, a fratura foi convenientemente reduzida, ocorreram menos complicações e o efeito curativo foi satisfatório. Nível de evidencia III, Estudo retrospectivo comparativo.

Descritores: Acetábulo. Fratura. Modificado. Pélvico. Resultado. Stoppa.

Citation: Hong-Zhang Guo, Yu-Fang He, Wan-Qing He. Modified stoppa approach for pelvic and acetabular fracture treatment. Acta Ortop Bras. [online]. 2019;27(4):216-9. Available from URL: http://www.scielo.br/aob.

\section{INTRODUCTION}

In recent years, with the rapid developments of industry and the transportation and shipping industry, the incidence rate of pelvic and acetabular fractures resulted from high energy injuries such as those caused by traffic accidents, high falling injury and crush by heavy objects have significantly increased, especially for pelvic fracture caused by traffic accidents. This type of fracture can lead to unmanageable complications such as bleeding; and in the short term, the conditions of these injuries are complex and prognosis is poor. For displaced pelvic and acetabular fractures, it is usually advocated by aggressive surgical treatment; ${ }^{1}$ and proper operative approach is very important for fracture exposure and reduction. There are many defects in the traditional ilioinguinal approach such as complicated anatomy, severe trauma, limited reduction and fixation spaces of fracture, and more complications. Since the application of the Stoppa incision approach was applied in the

All authors declare no potential conflict of interest related to this article.

Study was conducted at the Department of Orthopaedics, Gansu Provincial Hospital of TCM, Lanzhou, China.

Correspondence: Wan-Qing He. Department of Orthopaedics, Gansu Provincial Hospital of TCM, No.418 of Guazhou Road, Qilihe District, Lanzhou, China. 730050. wanqinghe_doc@163.com 
treatment of complicated hernia repair surgery and the treatment of pelvic and acetabular fractures by Hirvensalo et al., 2,3 the Stoppa approach and its modified approaches have became alternative approaches for traditional ilioinguinal approach due to advantages of slight trauma, replacement of the quadrilateral body fracture could be performed in direct vision, ${ }^{4}$ and less complications. Hence, the use of this approach has continuously increased. From November 2008 to September 2012, 18 cases of pelvic and acetabular fractures were treated by the modified Stoppa approach; and the curative effect was satisfactory. The report is as follows.

\section{MATERIALS AND METHODS}

\section{General data}

A total of 18 pelvis and acetabulum fracture patients who were admitted from November 2008 to September 2012 were enrolled into this study. All participants in the study provided written the free and informed consent in accordance with the Gansu Provincial Hospital of TCM Local Ethics Committee. Among these patients, 14 were males and four were females; and the age of these patients ranged between 19-62 years old, with an average age of 38.2 years old. Reasons of injuries: traffic accident injury (10 patients), falling injury (five patients), and crush injury (three patients). Time interval from injury to surgery was 6-18 days, with an average six days. All patients underwent three position- Judet Pelvic X-ray film photography, pelvis CT scans and two- or three-dimensional reconstructions. Among patients with pelvic fractures, Tile classification were as follows: two patients were ${ }^{5}$ B2 type, four patients were B3 type, and two patients were C2 type. Among the 10 patients with acetabulum fractures, according to Letournel-Judet classification: ${ }^{6}$ three patients had anterior column fractures, three patients had anterior column combined with posterior hemi-transverse shaped fractures, one patient had a T-type fracture, and one patient had a double column fracture. There was no vessel, nerve, or pelvic organ injury in preoperative patients. These patients were treated in accordance with the damage control principle of surgical treatment after admission. These preoperative examinations were improved. For Tile C-type fractures, $8-10 \mathrm{~kg}$ of weight traction was given on the condyles of the femur; and these were reviewed by X-ray films. Patients were operated after the pelvic vertical shift was corrected. For the remaining patients, when their conditions were stable, operation should be performed as early as possible; in which incision fracture reduction and internal fixation with steel plate and screw based on the Stoppa approach was performed. Among these patients, three were treated combined with the iliac fossa approach, and one was combined with the rear Kocher-Langenbeck (K-L) approach.

\section{Surgical methods}

Surgery was performed under general anesthesia. After successful anesthesia, the patients were placed in the supine position, and a triangular pillow was placed under the knees to place the patients in the genuflex and hip flexion posture. Treatments for double column fracture patients were combine with the posterior K-L approach, draped in accordance with the floating position, routine disinfection was performed, and a longitudinal incision of approximately 6-10 $\mathrm{cm}$ in length was made from the synchondrosis pubis to the navel. After the skin and subcutaneous tissue were incised, the linea alba was longitudinally incised, the rectus abdominis was pulled to both sides, and the ending point of the rectus abdominis was retained. Then, lower abdominal wall muscles, external iliac blood vessels, femoral nerves, and iliac and lumbar muscles were pulled forward anterolaterally, and extraperitoneal pelvic organs were pushed posteromedially. During the exposure process, surgeons should pay attention to the abnormal vascular extraperitoneal communication branches; which is the true pelvic brim from the synchondrosis pubis to the joints sacroiliaca, and could be exposed. In this group, arterial anastomotic branches between the inferior abdominal artery and obturator artery, as well as accompanying veins, were found in five patients; wherein the "corona mortis" vessel should be isolated and cut off. The iliopectineal fascia was incised, and the subperiosteal was dissected to expose the fractures. The fractures were reduced with apparatuses such as bucking bars and pelvic fracture reduction forceps, and were combined with lower limb traction. The fracture could be first fixed with screws and Kirschner wires, the steel plate was placed at the inner edge of the true pelvis entrance after plasticity, and the steel plate could be placed in the arcuate line and fossa iliaca after plasticity when necessary. During the operation, fracture reduction and the position and length of the screws in the steel plate were observed through C-arm fluoroscopy; and it was ensured that these screws would not enter into the acetabulum. The joints sacroiliaca or ilium fractures were reduced and fixed, and combined with the iliac fossa approach. For the case of double column fractures, the rear K-L approach was performed to reduce and fix the posterior column fracture in the floating posture, after the anterior column fracture was reduced by the improved Stoppa approach. The integrity of the peritoneum was checked, and a negative pressure drainage tube was placed at the retropubic space, the inner side or the posterior of the acetabulum. Then, the fascia recta was closely sutured, and then the skin was sutured.

\section{Postoperative treatment}

All post-operative patients received a subcutaneous injection of low-molecular-weight calciparine at the dose of 5,000 U for 12 days. Antibiotics were used at postoperative 24 hours to prevent infection. The negative pressure drainage were extracted within 24-48 hours post-operation, exercised the ankle joint of the affected limbs postoperatively woke up from the anesthesia. Hip joint functions combined with active and passive motions were exercised at two days after the operation, ground activities and partial weight-bearing were started 4-6 weeks post-operation, and the time of initiating full weight-bearing exercises depended on the review of the X-ray films.

\section{RESULTS}

In this study, operative incision length was 6-12 cm (average, $10 \mathrm{~cm}$ ) with the modified Stoppa approach, operative time duration was 50 150 minutes (average, 85 minutes), and the volume of intraoperative blood loss was 400-1,000 ml (average, $500 \mathrm{ml}$ ). Among these 18 patients, 12 patients revealed anatomical reductions in postoperative $\mathrm{X}$-rays; and the remaining were satisfactory reduction. According to the Matta standard, ${ }^{7}$ all 18 cases were satisfactory reduction. Curative effects were evaluated according to the Majeed standard: 813 patients were excellent, and five patients were good. These patients were postoperatively followed-up for 12 to 36 months, fracture healing time was 10-12 weeks, postoperative fat liquefaction of the abdominal wall incision occurred in one patient, and the wound healed two weeks after changing the dressing. No complications such as nonunion, heterotopic ossification, lower extremity deep vein thrombosis, or ureter bladder injuries occurred. Typical cases are shown in Figures 1-4.

\section{DISCUSSION}

\section{Selection of pelvic and acetabular fracture approaches}

The purpose of surgeries for pelvic and acetabular fractures are to correct deformities and restore pelvic ring structure stability, well-reduce acetabular fractures, and provide reliable fixations; in order to facilitate early functional exercise, and prevent the occurrence of traumatic arthritis of the hip. There are two main types of surgical approachs: one is the pelvic external rear K-L approach and the extended iliac approach, and the other is the pelvic internal ilioinguinal approach 


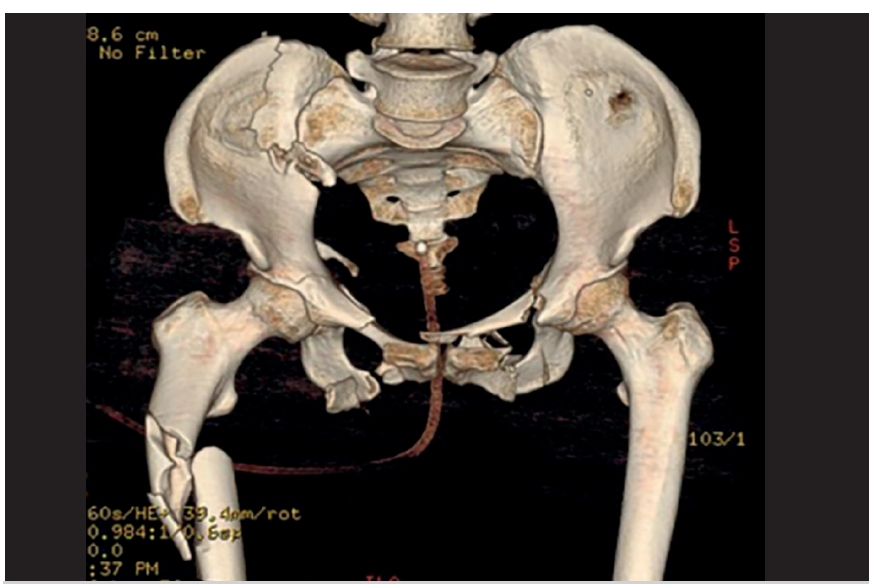

Figure 1. Via de acesso anterior de Russe para abordagem de pseudoartrose do escafoide.

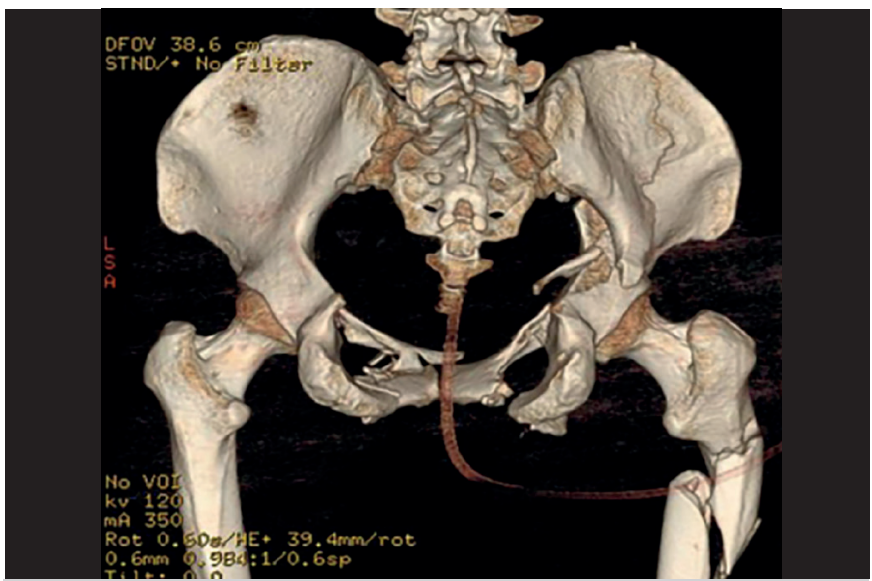

Figure 2. Female, 51 years old, pelvic fracture caused by falling from the high place, posteroanterior position showed by three dimensional rebuild CT image before surgery.

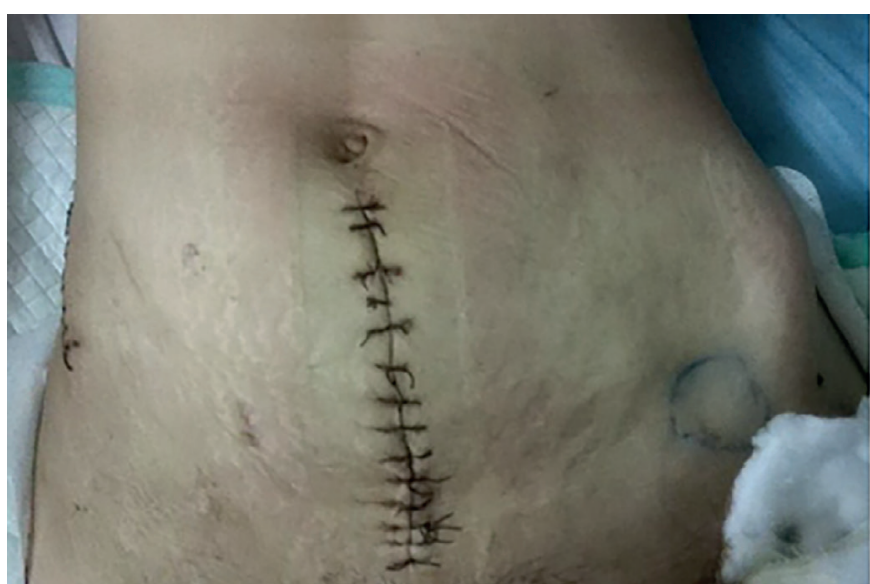

Figure 3. Female, 51 years old, pelvic fracture caused by falling from the high place, modified stoppa cut with right iliac fossa cut after surgery.

and the Pfannenstiel approach. The K-L approach was used for posterior fractures, while the ilioinguinal approach was used in anterior fractures. Anterior combined with posterior approaches, as well as the extended ilioinguinal approach, were used in double column fractures and other complex fractures. The ilioinguinal approach was used for the treatment of acetabular fractures by Letournel ${ }^{9}$ and Matta. ${ }^{10}$ This

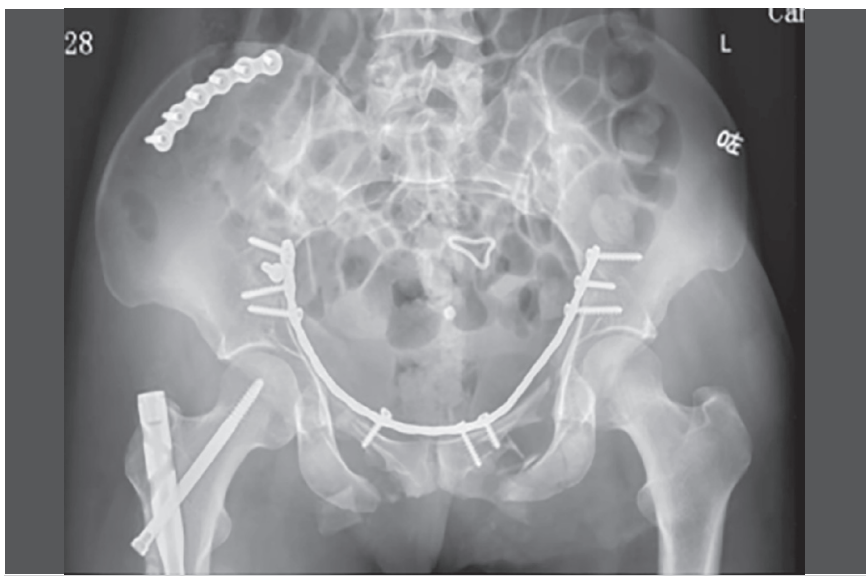

Figure 4. Female, 51 years old, pelvic fracture caused by falling from the high place, anteroposterior view radiographs of pelvic after surgery.

approach has advantages, in which the whole anterior ring of the pelvis, as well as the anterior acetabular fractures and transverse fracture, can be well revealed; reducing the incidence of heterotopic ossification and sciatic nerve injury. However, the anatomy of the ilioinguinal approach is complex; and the fractures need to be exposed in three windows of tissue spaces: the external iliac lymph vascular bundle, the femoral nerve, and the spermatic cord or the fallopian arch. The surgical trauma was great, technical requirements were high, the learning curve was steep, and it could easily cause damages to important tissues and other defects. Especially for fractures of the bilateral pelvic anterior ring and bilateral acetabulum, if the bilateral ilioinguinal approach was selected, greater trauma would be caused. In addition, the design of the ilioinguinal approach determined that this approach for the treatment of acetabular fractures is just like standing on the roof to repair the walls of a house; but the quadrilateral body fracture could not be treated under the direct vision. Furthermore, the Pfannenstiel approach reveals a limited range, which is generally limited to the treatment of synchondrosis pubis injury.

\section{Advantages of the Stoppa and modified Stoppa approaches}

The Stoppa approach ${ }^{11}$ was initially applied for the treatment of abdominal wall hernia. Hirvensalo et al applied this approach in pelvic fractures $^{12}$ and achieved good results. Subsequently, this approach was used for acetabular fractures after being improved by Cole and Bolhofner: ${ }^{13}$ early transverse incision, cutting off the ending points of the rectus abdominal were modified by abdominal median longitudinal incisions and the end-points of the rectus abdominal were reserved; which reduced the occurrence of abdominal wall hernias. This approach enters from the linea alba of the medial rectus abdominal. It does not need to be exposed, and stimulate the femoral artery and vein, femoral nerve, femoral lateral cutaneous nerve and other important tissues; and it is a soft tissue-friendly surgical approach. ${ }^{14}$ The surgeon should obtain a more open field of vision at the healthy lateral of the pelvis, and the synchondrosis pubis, quadrilateral body, and anterior of the articulationes sacroiliaca were extraperitoneally exposed. Furthermore, the ischial ramus could be partly exposed when the obturator fascia and fascia iliopectinea were stripped. Through measurement, a $79 \%$ scope of the inner true pelvis could be revealed; in particular, $80 \%$ of the surface of the quadrilateral body could be directly revealed. ${ }^{15}$ This was similar to stand inside the house to repair the wall. It had significant advantages of exposure and reduction, as well as the fixation of fractures, when compared with the ilioinguinal approach. ${ }^{16-18}$ Compared with the ilioinguinal approach, the modified Stoppa approach could reduce blood loss, reduce the amount of blood transfusion, and shorten operation time. ${ }^{19}$ 
Furthermore, the ilioinguinal approach can easily cause injuries to the iliac vein and the lateral femoral cutaneous nerve. ${ }^{20,21}$ There were no requirements of exposure and traction on the above tissues in the modified Stoppa approach, and no damages would be caused to these. In this study, there were no injuries occurred in iliac vessels, lateral femoral cutaneous nerves and femoral nerves.

\section{Application experience of the modified Stoppa approach and matters that need attention}

The modified Stoppa approach was applied to: anterior pelvic ring fractures, especially for unstable bilateral pubic ramus fractures, with or without pubic symphysis injury; anterior column and anterior wall fractures of the acetabulum, combined with the posterior half of the transverse fracture and T shape of the fracture, in which posterior column fracture displacement was not worse, and could be operated by a single modified Stoppa approach. The combination of the rear K-L approach could be applied to the complex fractures combined with posterior column and posterior wall fractures which were difficult to be reduced. This kind of operation model was applied to one of our patients. The injury in this operation model was significantly reduced compared with that of the ilioinguinal combined with the K-L approach, and postoperative recovery was faster. Acetabular quadrilateral body fracture combined with central femoral head dislocation could be treated via the modified Stoppa approach in a direct field of vision, which could significantly improve the quality of reduction, compared with the ilioinguinal approach. ${ }^{22}$ Since the modified Stoppa approach induces less trauma, good results had been obtained in elderly patients with unstable pelvic ring fractures, compared with the application of the ilioinguinal approach. ${ }^{23}$

\section{Contraindications}

The modified Stoppa approach is unfavorable when used ${ }^{24}$ in the following patients: patients with previous history of peritonitis and pelvic inflammatory disease; patients with a history of lower abdomen and pelvic cavity surgeries, and there were abdominal wall and peritoneal adhesion in these patients. Furthermore, this approach could not be replaced by the ilioinguinal approach. Patients who are too obese, patients injured for more than three weeks, and patients with serious displacement of double column fractures and iliac crest fractures are not suitable to be treated with this approach.

\section{Some experiences}

(1) Preoperative placement of a bolster under the knees, and the posture of the genuflex and hip flexion could effectively improve the exposure and reduction process during operation. (2) Care should be taken in protecting the iliac vessels bundles with a wet gauze when these were anterolaterally stretched, must not perform excessive traction; prevent damage to the external iliac vein to avoid serious consequences, perform intraoperative indwell catheterization, and attention should be given in protecting the bladder. (3) The obturator vascular nerve bundles must not be excessively retracted inward posteriorly to avoid injury. (4) If the length of the drill bit is not enough, the $3.0 \mathrm{~mm}$ Kirschner wire could be used instead; wherein the Kirschner wire can be used to drill a hole in a certain radian, which is conducive for adjusting the direction of the screw. (5) Since the fixation was performed in the inner walls of the pubic branch and quadrilateral body, we can make full use of the pressing and pulling effects produced by the combination of steel plate and screw to reduce the fracture. (6) The combined application of the iliac fossa approach could be used in the acetabular fracture combined with the iliac wing fracture and high anterior column fractures.

\section{CONCLUSION}

The modified Stoppa approach for the treatment of pelvic and acetabular fractures has advantages of less trauma, adequate and rapid exposure, convenient and effective fracture reduction and fixation, less complications and better postoperative recovery. Furthermore, this could be used as an alternative approach of the ilioinguinal approach. However, the clinical value of this approach remains to be verified by large sample cases due to the small number of cases and short follow-up time in this study.

AUTHORS' CONTRIBUTIONS: HZG (0000-0002-6988-0574)*: substantial contributions to the conception and design of the work. HZG, YFH (0000-0001$5208-8655)^{\star}$, WQH,$(0000-0002-1286-0353)^{*}$ : the acquisition, analysis, and interpretation of data for the work. WQH revising it critically for important intellectual content. HZG, WQH, final approval of the version to be published. HZG, WQH, agreement to be accountable for all aspects of the work in ensuring that questions related to the accuracy or integrity of any part of the work are appropriately investigated and resolved. *ORCID (Open Researcher and Contributor ID).

\section{REFERENCES}

1. Min BU, Nam SY, Kang CS. Complications of surgical treatment in patients with acetabular fractures. J Korean Hip Soc. 2000;12(3):253-60.

2. Hirvensalo $\mathrm{E}$, Lindahl J, Böstman $\mathrm{O}$. A new approach to the internal fixation of unstable pelvic fractures. Clin Orthop Relat Res. 1993;(297):28-32.

3. Hirvensalo E, Lindahl J, Kiljunen V. Modified and new approaches for pelvic and acetabular surgery. Injury. 2007;38(4):431-41.

4. Collinge CA, Lebus GF. Techniques for reduction of the quadrilateral surface and dome impaction when using the anterior intrapelvic (modified Stoppa) approach. J Orthop Trauma. 2015;29 Suppl 2:S20-4.

5. Tile M, Helfet DL, Kellam JF. Fractures of the acetabulum, ed 3. Philadelphia: Lippincott, Williams \& Wilkins; 2003.

6. Letournel E, Judet R. Fractures of the acetabulum[M]. 2nd ed. New York: Springer-Verlag; 1993

7. Matta JM, Tornetta P 3rd. Internal fixation of unstable ring injuries. Clin Orthop Relat Res. 1996;(329):129-40.

8. Majeed SA. Grading the outcome of pelvic fractures. J Bone Joint Surg (Br). 1989;71(2):304-6.

9. Letournel E. Acetabulum fractures: classification and management. Clin Orthop Relat Res. 1980;(151):81-106

10. Matta JM. Operative treatment of acetabular fractures through the ilioinguina approach: A 10 year perspective. J Orthop Trauma. 2016;20(1 Suppl):S20-9.

11. Stoppa RE, Rives JL, Warlaumont CR, Palot JP, Verhaeghe PJ, Delattre JF. The use of Dacron in the repair of hernias of the groin. Surg Clin North Am. 1984;64(2):269-85

12. Rives J, Stoppa R, Fortesa L, Nicaise H. Dacron patches and their place in surgery of groin hernia: 65 cases collected from a complete series of 274 hernia operations. Ann Chir. 1968;22(3):159-71.

13. Cole JD, Bolhofner BR. Acetabular fracture fixation via a modified Stoppa limited intrapelvic approach: description of operative technique and preliminary treatment results. Clin Orthop Relat Res. 1994;(305):112-23.

14. Lehmann W, Fensky F, Hoffmann M, Rueger JM. The stoppa approach for treatment of acetabular fractures. Z Orthop Unfall. 2014;152(5):435-7.

15. Bible JE, Choxi AA, Kadakia RJ, Evans JM, Mir HR. Quantification of bony pelvic exposure through the modified Stoppa approach. J Orthop Trauma. 2014;28(6):320-3.

16. Sagi HC, Afsari A, Dziadosz D. The anterior intra-pelvic (modified rives-stoppa) approach for fixation of acetabular fractures. J Orthop Trauma. 2010;24(5):263-70.

17. Elmadag M, Guzel Y, Aksoy Y, Arazi M. Surgical Treatment of Displaced Acetabular Fractures Using a Modified Stoppa Approach. Orthopedics. 2016;39(2):e340-5.

18. Keel MJ, Bastian JD, Büchler L, Siebenrock KA. Anterior approaches to the acetabulum. Unfallchirurg. 2013;116(3):213-20.

19. Ma K, Luan F, Wang X, Ao Y, Liang Y, Fang Y, et al. Randomized, controlled trial of the modified Stoppa versus the ilioinguinal approach for acetabular fractures. Orthopedics. 2013;36(10):e1307-15.

20. Letournel $\mathrm{E}$. The treatment of acetabular fractures through the ilioinguinal approach. Clin Orthop Relat Res. 1993;(292):62-76.

21. Judet R, Judet J, Letournel E. Surgical treatment of recent fractures of the acetabulum: apropos of 46 operated cases. Mem Acad Chir (Paris). 1962:88:369-77.

22. Casstevens C, Archdeacon MT, d'Heurle A, Finnan R. Intrapelvic reduction and buttress screw stabilization of dome impaction of the acetabulum: a technical trick. J Orthop Trauma. 2014;28(6):e133-7.

23. Bastian JD, Ansorge A, Tomagra S, Siebenrock KA, Benneker LM, Büchler L, et al. Anterior fixation of unstable pelvic ring fractures using the modified Stoppa approach: mid-term results are independent on patients' age. Eur J Trauma Emerg Surg. 2016;42(5):645-60.

24. Kim HY, Yang DS, Park CK, Choy WS. Modified Stoppa approach for surgical treatment of acetabular fracture. Clin Orthop Surg. 2015;7(1):29-38. 